\title{
Strong stimulation of recombinant protein production in Escherichia coli by combining stimulatory control elements in an expression cassette
}

Friederike Zwick, Rahmi Lale and Svein Valla*

\begin{abstract}
Background: The XyIS/Pm expression system has been used to produce recombinant proteins at industrial levels in Escherichia coli. Activation of transcription from the Pm promoter takes place in the presence of benzoic acid or derivatives of it. Previous mutagenesis studies resulted in identification of several variants of the expression control elements xy/S (X), Pm (P) and the 5'-untranslated region $(U)$ that individually gave rise to strongly stimulated expression. The goal of this study was to test if combination of such stimulatory mutations in the same expression vectors would lead to further increase of expression levels.

Results: We combined X, P and U variants that were originally identified due to their ability to strongly stimulate expression of the reporter gene bla (resistance to penicillin). Combination of optimized elements stimulated bla expression up to 75 -fold ( $\mathrm{X}, \mathrm{P}$ and $\mathrm{U}$ combined) relative to the wild-type system, while accumulated transcript levels increased about 50-fold. This is much more than for the elements individually. We also tested combination of the variant elements on two other and unrelated genes, celB (encoding phosphoglucomutase) and the human growth factor gene gm-csf. Protein production from these genes is much more efficient than from bla in the wild-type system, but expression was still significantly stimulated by the combination of $X, P$ and $U$ variants, although not to the same extent as for bla.

We also integrated a single copy of the expression cassette with each gene into the $E$. coli chromosome and found that the expression level from this single copy was higher for bla than for the wild-type plasmid system, while it was lower for celB and gm-csf.
\end{abstract}

Conclusion: Our results show that combination of stimulatory expression control elements can be used to further increase production of different proteins in E. coli. For one reporter gene (b/a) this allowed for more protein production from a single gene copy integrated on the chromosome, compared to the wild-type plasmid system. The approach described here should in principle be applicable for improvement of any expression cassette.

Keywords: Recombinant, XyIS/Pm, UTR, Gene expression, Promoter, Mutant, Escherichia coli

\footnotetext{
* Correspondence: svein.valla@biotech.ntnu.no

Department of Biotechnology, Norwegian University of Science and

Technology, Sem Sælands Vei 6/8, N-7491, Trondheim, Norway
} 


\section{Background}

Plasmids are heavily utilized as expression tools for recombinant protein production in bacteria, mainly because they enable easy introduction of recombinant genes at high gene dosages, resulting in large amounts of transcripts from the gene of interest [1]. However, high plasmid copy numbers in itself represent a burden for the host [2-4], and this may lead to problems like plasmid instability, decreased growth rates, and plasmid DNA mutations [2,5-8]. Antibiotic selection markers included on plasmids for enhanced stability also impose an additional metabolic burden to the cell [9].

Ideally it would therefore be advantageous to avoid such autonomously replicating elements and chromosomal integration of expression cassettes stands as an attractive alternative for stable expression [10,11].

The main problem with single copy chromosomal integrations is that the strong reduction in gene dosage compared to high copy number plasmids leads to reduced transcript formation and will therefore require very efficient translation of each transcript. Increasing the number of copies of the gene of interest on the chromosome could potentially eliminate this problem, but this requires further modification of the host genome in order to ensure the stability of the multiple times integrated DNA [11]. It is therefore important to develop methods that aim for the highest possible levels of expression per gene copy, as this might allow reduction of the number of gene copies per cell. A recent study demonstrates an approach to ensure high levels of transcript formation, by placing the desired gene together with a tandem tac promoter cluster into the chromosome [12]. This method eliminates the problem of having multiple copies of the gene, however the promoter utilized is constitutive. For metabolic engineering type applications it is desirable to have time-dependent expression.

We have previously demonstrated that the strong and positively regulated $x y l S / P m$ expression cassette in its wild-type form, combined with a mini-RK2 replicon, can serve as a tool to achieve industrial level production of recombinant proteins in Escherichia coli [13,14]. XylS belongs to the AraC-XylS transcriptional regulator family and in the presence of passively transported benzoic acid derivates it activates transcription from the $P m$ promoter.

More recently, we have shown that expression from $\mathrm{Pm}$ can be further strongly stimulated by introducing mutations in the promoter region [15], in the 5'-untranslated region of mRNA (5'-UTR) [16], or in the XylS regulator coding sequence [17]. In this study we show that combination of such previously identified variant DNA control elements leads to additive stimulatory effects on expression, and this approach should in principle be applicable to any expression system.

\section{Results}

The expression level from Pm can be strongly stimulated by combining mutated DNA elements previously shown to individually enhance expression

Initial studies involving combinations of previously isolated stimulatory control element variants $(P m$ promoter, its UTR and $x y l S$ ) indicated that they at least to some extent acted additively, and based on these observations cells containing eight different plasmids were subjected to more detailed analyses. A plasmid with only wild-type elements was used as control, and in addition we constructed three plasmids containing one variant element only (comX, comP, comU), three constructs with each possible combination of two variant elements (comXP, comXU, comPU), and one construct (comXPU) in which all three elements were combined (Table 1). The three variants used were the $x y l S$ variant StEP-13 (X), which carries five amino acid substitutions and stimulates transcription [17]; a promoter variant $(\mathrm{P})$ designated ML2-5 which carries five point mutations in $\mathrm{Pm}$, also stimulating transcription [15]; and a 5'-UTR variant (U) designated H39 with two point mutations (Figure 1), which appears to predominantly stimulate translation.

To monitor the expression from the different variants and the combination of them we first used bla (encoding $\beta$-lactamase) as a reporter gene. This gene was also used as a reporter to originally identify the variant sequences,

Table 1 Expression profiles of $E$. coli DH5a cells containing the indicated constructs

\begin{tabular}{|c|c|c|c|c|c|c|}
\hline Combinations & xylS & $P m$ & 5'-UTR & Induced* & Uninduced* & Reference \\
\hline wild-type & wild-type & wild-type & wild-type & $0.2-0.4$ & $0.005-0.01$ & This study \\
\hline comP & wild-type & ML2-5 & wild-type & $1-2$ & $0.005-0.01$ & {$[15]$} \\
\hline comU & wild-type & wild-type & H39 & $2-3$ & $0.06-0.08$ & This study \\
\hline $\operatorname{com} X$ & StEP-13 & wild-type & wild-type & $1-2$ & $0.02-0.03$ & {$[17]$} \\
\hline comPU & wild-type & ML2-5 & H39 & $5-6$ & $1-1.5$ & This study \\
\hline $\operatorname{com} X P$ & StEP-13 & $M L 2-5$ & wild-type & $3-4$ & $0.3-0.4$ & This study \\
\hline $\operatorname{com} X U$ & StEP-13 & wild-type & H39 & $12-13$ & $0.8-0.9$ & This study \\
\hline comXPU & StEP-13 & ML2-5 & H39 & $15-20$ & $3-4$ & This study \\
\hline
\end{tabular}

* Phenotypes are given as ampicillin resistance levels $\left(\mathrm{mg} \mathrm{mL}^{-1}\right)$ under induced $(0.1 \mathrm{mM}$ m-toluate) and uninduced conditions. 


\begin{tabular}{|c|c|c|}
\hline \multirow[t]{7}{*}{$\frac{x}{s}$} & $\begin{array}{l}\text { xyls variants } \\
\text { StEP-13 }\end{array}$ & F3Y, I50T, F97L, E195G, M196T \\
\hline & & $\begin{array}{l}\text { Transcriptional } \\
\text { start site }\end{array}$ \\
\hline & $P m$ variants & - BspLU11I \\
\hline & $\begin{array}{l}\text { wild-type } \\
\text { ML2-5 }\end{array}$ & 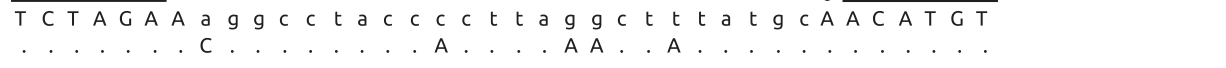 \\
\hline & & SD \\
\hline & 5'-UTR variants & - BspLU11I \\
\hline & $\begin{array}{l}\text { wild-type } \\
\text { H39 }\end{array}$ & 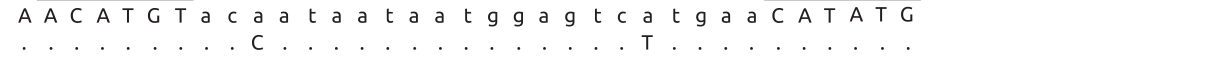 \\
\hline $\begin{array}{l}\text { Figure } 1 \text { Sequence } \\
\text { randomly mutageni: } \\
P m \text { and 5'-UTR varia } \\
\text { translational start sit }\end{array}$ & $\begin{array}{l}\text { profiles of the } \\
\text { zed bases, and in } \\
\text { ents). Identical nu } \\
\text { are written in }\end{array}$ & $\begin{array}{l}\text { variants that are used in this study. Restriction sites shown are unique. Nucleotides in lower case indicate } \\
\text { troduced mutations are indicated for each construct (amino acid substitutions for XylS, and base changes for } \\
\text { cleotides are indicated by dots, deletion mutations are indicated by short horizontal lines. Transcriptional and } \\
\text { bold face and indicated with filled circles. SD is the putative Shine-Dalgarno sequence. }\end{array}$ \\
\hline
\end{tabular}

based on the observation that host tolerance against ampicillin correlates with the amounts of $\beta$-lactamase produced [15-17]. The bla gene was in all cases expressed from the relevant variant version of the plasmid pTA16 (Figure 2).

The expression level from $\mathrm{Pm}$ can be continuously adjusted by varying the inducer concentration [18-20], and in the tests of the different combination constructs we used a low concentration $(0.1 \mathrm{mM})$ to avoid potential host toxicity effects caused by elevated expression levels of $\beta$-lactamase. Plating of the host strains containing the plasmid variants on agar medium supplied with varying concentrations of ampicillin demonstrated that under induced conditions cells containing the wild-type, comX, comP and comU plasmid constructs tolerated up to 0.2 , 1,1 , and $2 \mathrm{mg} \mathrm{mL}^{-1}$ of the antibiotic, respectively (Table 1). Interestingly, all three combinations of the two variant elements, comXP, comXU and comPU, resulted in varying but further enhancement of target protein expression, observed as upper tolerance levels of 3,12 , and $5 \mathrm{mg} \mathrm{mL}^{-1}$ ampicillin, respectively. The effect

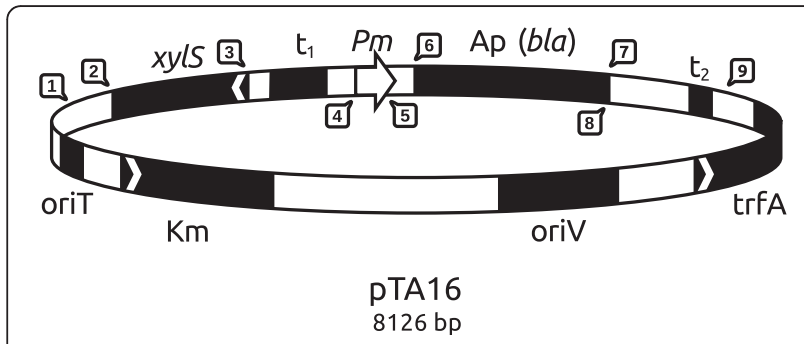

Figure 2 Map of plasmid pTA16. $P$ m, positively regulated promoter; xylS, gene encoding Pm activator; $A p^{r}$ (bla), ampicillin resistance gene encoding $\beta$-lactamase; $\mathrm{Km}^{r}$, kanamycin resistance gene; $t r f A$, gene encoding the essential replication protein; oriV, origin of vegetative replication; oriT, origin of conjugal transfer; $t 1$, rrnBT/T2 bidirectional transcriptional terminator; $t 2$, bidirectional transcriptional terminator. Restriction sites shown are unique: 1-Sfil, 2-Agel, 3-Sacl, 4-Xbal, 5-BspLUIII, 6-Ndel, 7-Notl, 8-BamH1, 9-Kpn1. was even more drastic for comXPU, which tolerated up to $15 \mathrm{mg} \mathrm{mL}^{-1}$ of ampicillin. This is 75 -fold higher than for cells with the wild-type plasmid. The uninduced resistance levels also went up for all strains (up to $3 \mathrm{mg} \mathrm{mL}^{-1}$ for comXPU).

Ampicillin resistance is a good indicator of expression at the protein level, but cannot be used for accurate quantitative comparisons between clones. We therefore directly measured the corresponding $\beta$-lactamase enzyme activities. Combination of two elements in all cases stimulated expression at the protein level, about 6-fold for comXP, 25-fold for comPU, 50-fold for comXU and 75-fold for comXPU (Figure 3a). These data are in good agreement with the observed stimulation of ampicillin resistance.

The levels of accumulated transcripts of the target gene were also measured by relative quantification realtime RT-PCR (qRT-PCR), and as expected a strong stimulation was observed (up to about 63-fold for comXPU), although somewhat less than at the protein level (Figure 3a). This presumably reflects that some of the stimulation is resulting from improved translation of the target gene, most clearly demonstrated by comXU.

\section{Combination of variant elements also leads to increased expression of two other tested reporter genes}

As for any expression system individual proteins are expressed at quite varying levels from $P m$, and $\beta$-lactamase is not among the highly expressed proteins. In the original identification of the $\mathrm{X}, \mathrm{P}$ and $\mathrm{U}$ variants the bla gene was used as a reporter and it is therefore of interest to study if the variant combinations would also stimulate the expression of genes other than bla. We selected the bacterial $c e l B$ gene (encoding phosphoglucomutase) and the human gm-csf gene (encoding cytokine granulocytemacrophage colony-stimulating factor) as representative examples for such an analysis. Both of these genes were previously (in contrast to bla) shown to be efficiently 


\begin{tabular}{llll} 
a) & & & \\
& xyls & $P m$ & 5'-UTR \\
\hline Wild-type & wild-type & wild-type & wild-type \\
comX & StEP-13 & wild-type & wild-type \\
comP & wild-type & ML2-5 & wild-type \\
comXP & StEP-13 & ML2-5 & wild-type \\
comU & wild-type & wild-type & H39 \\
comPU & wild-type & ML2-5 & H39 \\
comXU & StEP-13 & wild-type & H39 \\
comXPU & StEP-13 & ML2-5 & H39
\end{tabular}

b)

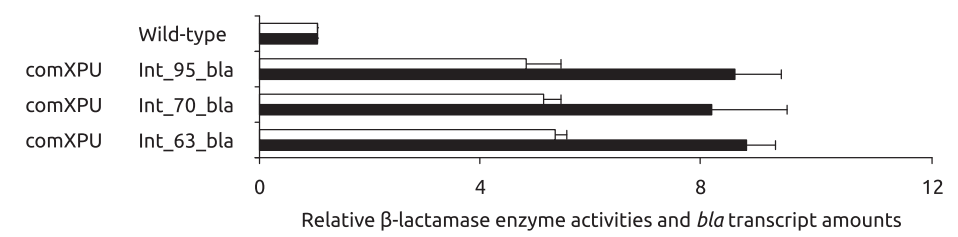

Figure 3 -lactamase enzyme activities and bla transcript amounts for extra-chromosomally (a) and chromosomally (b) expressed combination constructs. Enzyme activities in white, transcript amounts in black, all values are relative to the wild-type (arbitrarily set to 1). The values are the average of at least two biological replicas. E. coli DH5a was used as host.

expressed from wild-type $x y l S / P m$. CelB was earlier found to be the clearly dominating protein on a crude gel when expressed from wild-type xylS/Pm [21] and also GM-CSF could be visualized on a protein gel when expressed from a plasmid with elevated copy number [14]. The bla gene in the constructs described above was therefore substituted with either the $c e l B$ or the gm-csf gene. Phosphoglucomutase enzyme activities were then measured, while GM-CSF protein levels were visualized by Western Blotting (Figures $4 \mathrm{a}$ and $5 \mathrm{a}$ ). In case of gm-csf another strain (RV308) was used as host to enable comparison of expression levels to previously published results [14]. Comparisons of ampicillin tolerances and analyses of gm-csf expression at the transcript and protein levels in DH5 $\alpha$ andRV308 indicated that absolute values are slightly higher in RV308, while all relative values, compared to wild-type, were similar in both strains (data not shown).

Interestingly, expression of both genes was quite significantly stimulated at the protein level, particularly with the comXPU construct (about 8.5-fold for celB). For $g m$-csf protein production was difficult to detect by Western blotting, but we have shown before that it is easily detectable if a copy up (3-4 fold) version of the same plasmid is used [14]. Compared to this construct the comXPU variant (at wild-type plasmid copy number)

\begin{tabular}{llll} 
a) & xyls & Pm & 5'-UTR \\
\hline Wild-type & wild-type & wild-type & wild-type \\
comPU & wild-type & ML2-5 & H39 \\
comXU & StEP-13 & wild-type & H39 \\
comXP & StEP-13 & ML2-5 & wild-type \\
comXPU & StEP-13 & ML2-5 & H39
\end{tabular}

b)

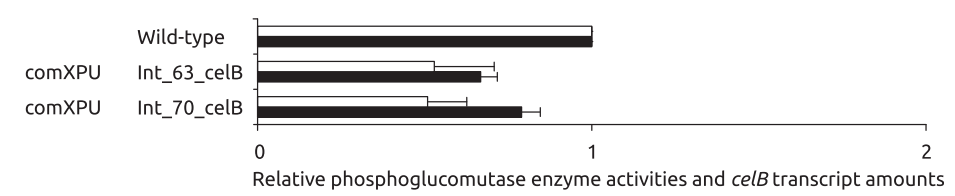

Figure 4 Phosphoglucomutase enzyme activities and celB transcript amounts for extra-chromosomally (a) and chromosomally (b) expressed combination constructs. Enzyme activities in white, transcript amounts in black, all values are relative to the wild-type (arbitrarily set to 1). The values are the average of at least two biological replicas. E. coli DH5a was used as host. 


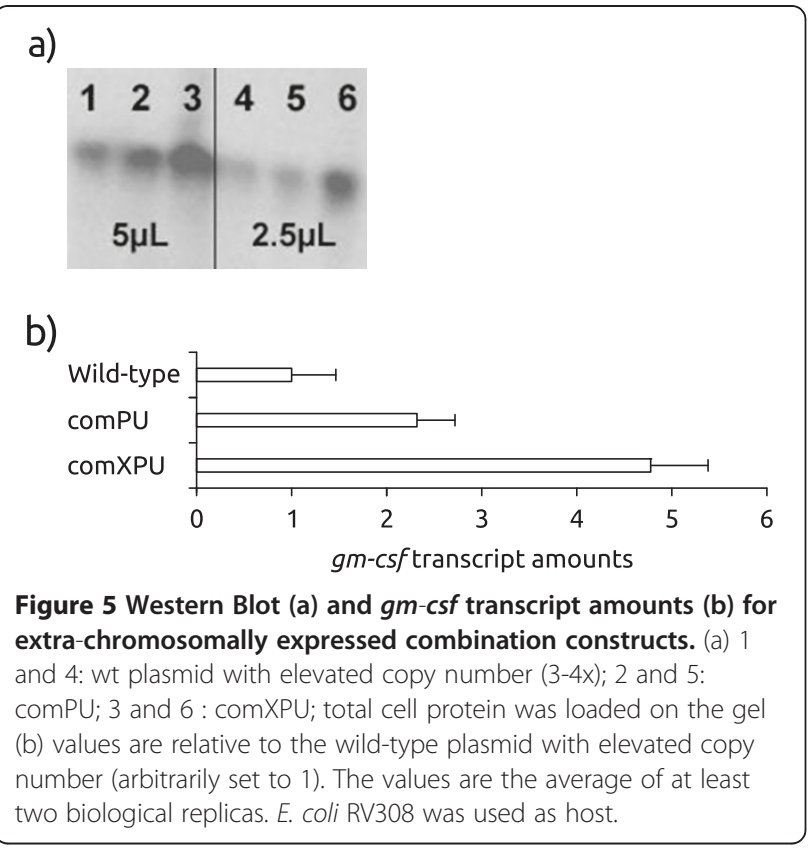

produced between 3 and 4-fold more GM-CSF. This means that the level of stimulation per gene copy is probably around ten-fold and the protein was now clearly visible on a crude gel, without the need for Western Blotting.

We also monitored the stimulation at the transcript level, and interestingly, for $c e l B$ the comXPU construct stimulated accumulation of target gene transcripts more (about 15-fold) than at the protein level (Figure 4b). This might be interpreted to indicate inclusion body formation but we have found that this particular protein does not to any significant extent form inclusion bodies (data not shown). We therefore conclude that under the reported conditions (with comXPU) the excessive transcript amounts cannot be efficiently handled by the translational machinery. For gm-csf the transcriptional stimulation was also highest for comXPU (4.8-fold), compared to the wild-type plasmid with wild-type copy number (Figure 5b).

Based on all these studies we conclude that the variant expression control elements isolated in the context of the bla gene also are able to stimulate the expression of other and very unrelated genes, although not to the same extent. The reason for this difference may either be that the variant expression elements are particularly well adapted to bla, or that the more efficient expression of $c e l B$ and gm-csf in the wild-type system gives less room for further improvements.

\section{Chromosomal integration of genes may be a future option for optimized expression cassettes}

Ideally chromosomal integrations can be seen as desirable in protein expression, due to greater genetic stability of the production strains. We have studied this for bla, celB and gm-csf, using the expression cassette with the comXPU variant, integrated into the $E$. coli chromosome (strain DH5 $\alpha$ for bla, celB, and strain RV308 for gm-csf) by use of conditional-replication, integration and modular (CRIM) plasmids [22]. These replicons facilitate directed integration of a DNA-fragment at different locations in $E$. coli chromosome at bacterial attachment sites (attB). The $x y l S / P m$ expression cassette with the three target genes was PCR-amplified and cloned into the integration plasmids, and successful insertion of single copies was confirmed by a PCR procedure described by Haldimann and Wanner [22]. Expression levels of the resulting strains were tested both by enzyme assays or Western Blots and qRT-PCR. For each gene the results were similar independent of the integration sites, and for $\beta$-lactamase the final protein expression was about 8-fold higher relative to the wild-type plasmid system (Figure $3 \mathrm{~b}$ ). For $c e l B$ the corresponding levels were slightly lower than that of the wild-type cassette in the plasmid (Figure $4 \mathrm{~b}$ ), and for GM-CSF the protein was not detectable on a Western Blot (data not shown).

At the transcriptional level stimulation of bla expression was somewhat lower than at the translational level, as for $\mathrm{XPU}$ in the plasmid state. In contrast, for $c e l B$ the transcription was much more stimulated in the plasmid state. For $g m$-csf accumulated transcript levels were about 5 -fold lower than for the corresponding wild-type plasmid with wild-type copy-number (not shown).

In conclusion the results show that combination of optimized variant sequences in the expression control system lead to additive effects that can be used to strongly stimulate expression, but not sufficiently for single copy chromosomal integrations to reach the maximum expression levels obtained by the use of optimized plasmids. It may be possible to overcome this bottleneck by other means (see Discussion).

\section{Discussion}

The wild-type $x y l S / P m$ expression cassette has previously been found to express at least some proteins at industrial levels under high cell density conditions [13,14]. It is well known that no expression system can guarantee high levels of expression for any protein, and the reasons for this are obviously related to features of each specific gene or the protein encoded by it. It will in any case be important to use optimized inducible expression cassettes, particularly if the expression-stimulating features are acting on most genes. Most systems used for protein expression in E. coli are based on promoters that utilize the host RNA polymerase, with the exception of the bacteriophage T7 RNA polymerase based systems which appears to be prone to genetic instability [23]. 
From the results described here it is clear that the $x y l S / P m$ cassette could be further improved relative to its wild-type version, and we believe that this potential has not yet been exhausted. It will clearly be important to reduce the enhanced uninduced expression level which was a consequence of the stimulated expression.

One important outcome of the studies reported here is that the improvement of the expression cassette seems to be valid at least to some extent for genes other than the one $(b l a)$ used to identify the variants. It appears likely that mutations stimulating transcription (X and $\mathrm{P}$ ) might have a more universal effect than those stimulating translation $(\mathrm{U})$, although we have found that sequences in the 5'-UTR region (or its corresponding DNA) may also affect transcription initiation rate [16]. The 5'-UTR may form secondary structures that potentially involve parts of the coding sequence of the gene to be expressed, but such problems can to some extent be predicted by bioinformatics analyses. It would be unrealistic to expect that all genes should respond quantitatively similar to changes in the sequences of the expression cassette, since the absolute expression levels vary over a wide range. This may explain most of the quantitative response differences observed among the genes tested in this study.

Chromosomal integration of genes to be expressed is an attractive approach in recombinant protein production, as it most likely will be associated with greater genetic stability. This approach appears to be possible for the T7 system if the growth conditions are modified and prolonged production times are considered acceptable [10], and also with a tandem used constitutive tac promoter system [12]. The study reported here indicates that under standard shake-flask conditions the integrated engineered $\mathrm{XylS} / \mathrm{Pm}$ system can lead to enough transcript formation to allow expression levels comparable to those obtained by a plasmid-mediated system. Further improvement may be achieved by optimization of the growth conditions and we have also recently found (unpublished) that the level of expression is very sensitive to the intracellular concentration of the XylS regulator, a potential bottleneck that may be solved without the need for plasmids.

\section{Conclusions}

Our results clearly show that previously identified stimulatory expression control elements for the inducible $x y l s / P m$ cassette can be combined in one expression vector to further improve expression levels. We found this valid also for genes other than the one used to identify the variants in the first place. For bla this resulted in higher expression from a single chromosomally integrated gene copy than from the corresponding wild-type plasmid system. The approach used here should be applicable also to other expression cassettes and such optimized systems should represent a good starting point for the goal of producing recombinant proteins without the need for extra-chromosomal replicons.

\section{Methods}

Strains and growth conditions

Escherichia coli DH5 $\alpha$ (Bethesda Research Laboratories) was used as a host for cloning and expression studies unless otherwise stated. Cells were grown in Luria-Bertani (LB) broth (10 $\mathrm{g} \mathrm{L}^{-1}$ tryptone, $5 \mathrm{~g} \mathrm{~L}^{-1}$ yeast extract, and $5 \mathrm{~g} \mathrm{~L}^{-1} \mathrm{NaCl}$ ) or on LB agar (LB broth with $20 \mathrm{~g} \mathrm{~L}^{-1}$ agar) at $37^{\circ} \mathrm{C}$, except for in expression studies, where $30^{\circ} \mathrm{C}$ was used. Kanamycin $\left(50 \mu \mathrm{g} \mu \mathrm{L}^{-1}\right)$ was used for selection purposes.

For expression studies with gm-csf Escherichia coli RV308 (ATCC 31608) was used as host to facilitate comparison with previously published results [14]. Cells were grown at $30^{\circ} \mathrm{C}$ in HiYe medium $\left(8.6 \mathrm{~g} \mathrm{~L}^{-1} \mathrm{Na}_{2} \mathrm{H}\right.$ $\mathrm{PO}_{4} \cdot 2 \mathrm{H}_{2} \mathrm{O}, 3 \mathrm{~g} \mathrm{~L}^{-1} \mathrm{KH}_{2} \mathrm{PO}_{4}, 1 \mathrm{~g} \mathrm{~L}^{-1} \mathrm{NH}_{4} \mathrm{Cl}, 0.5 \mathrm{~g} \mathrm{~L}^{-1}$ $\mathrm{NaCl}, 2 \mathrm{~g} \mathrm{~L}^{-1}$ glucose, $10 \mathrm{~g} \mathrm{~L}^{-1}$ glycerol, $10 \mathrm{~g} \mathrm{~L}^{-1}$ yeast extract, $2.5 \mathrm{mM} \mathrm{MgSO}$, $250 \mu \mathrm{M} \mathrm{Fe}(\mathrm{III})$-citrate, $49 \mu \mathrm{M}$ $\mathrm{H}_{3} \mathrm{Bo}_{3}, 79 \mu \mathrm{M} \mathrm{MnCl}, 23 \mu \mathrm{M}$ EDTA, $9 \mu \mathrm{M} \mathrm{CuCl}$, $10 \mu \mathrm{M} \mathrm{Na}_{2} \mathrm{MoO}_{4}, 11 \mu \mathrm{M} \mathrm{CoCl} 2,36 \mu \mathrm{M} \mathrm{Zn}$-acetate) and induced by addition of $0.5 \mathrm{mM}$ m-toluate.

\section{Construction of plasmids and chromosomal integrations}

The plasmid pTA16 was used as basis vector for construction of the combinations. pTA16 is a derivative of pIB11 [16], in which Agel and Sacl restriction sites were introduced at either end of the $x y l S$ gene. The $x y l S$ variants were obtained from the corresponding plasmids [17] upon digestion with Agel and Sacl. The bla gene was replaced by celB by the use of NdeI and BamHI restriction sites, and zby gm-csf by the use of NdeI and KpnI restriction sites. Agarose gel purifications were performed by QIAquick gel extraction kit (Qiagen). Pm and 5'-UTR variants were ordered synthetically (Eurofins MWG Operon, Germany) and were designed to carry overhangs suitable for cloning, Xbal/BspLUllI, and BspLUlll/Ndel, respectively. All constructs were confirmed by sequencing, performed by Eurofins MWG Operon (Germany).

The $x y l S / P m$ expression cassette both with bla, celB and $g m-c s f$ as reporter gene was PCR-amplified with the primer set 5'-AAACACTAGTTCAGAGCTTGGAGAG3' and 5'-CATAAAGCTGACTCTAGCTA-3' from plasmids pTA16_comXPU_bla, pTA16_comXPU_celBand pTA16_ comXPU_gmcsf, respectively, and were cloned as BamHI/ Spel-fragments (bla, celB) or KpnI/SpeI-fragments (gm-csf) into the integration plasmids. Chromosomal integration of the resulting plasmids was performed as described by Haldimann and Wanner [22].

The plasmids pAH63, pAH70 and pAH95 with the corresponding helper plasmids pINT-ts $\left(a t t_{\lambda}\right)$, pAH69 
$\left(a t t_{\mathrm{HK} 022}\right)$ and pAH121 $\left(a t t_{\mathrm{P} 21}\right)$, respectively, were chosen for integration. Genomic location of the integration sites in the $E$. coli K-12 genome sequence are: for $a t t_{\lambda}$ 806551, for $a t t_{\mathrm{HK} 022} 1055412$ and for att $_{\mathrm{P} 21} 1210637$ [24]. Successful integration could be confirmed for all three bla-constructs and for each two of the $c e l B$ - and gmcsf-constructs. The integrants were named based on the $\mathrm{pAH}$ plasmids and the reporter genes used (Int_63_bla, Int_70_bla, Int_95_bla, Int_63_celB, Int_ 70_celB, Int_63_gmcsf, Int_70_gmcsf).

\section{Standard DNA manipulations}

Transformations of $E$. coli were performed with a modified $\mathrm{RbCl}$ protocol (Promega) in cloning experiments. Wizard Plus SV mini preps DNA purification kit (Promega) was used for plasmid DNA purifications. Enzymatic manipulations were performed as described by the manufacturers. PCR reactions were performed using the Expand high fidelity PCR system kit (Roche).

\section{Enzyme assays}

For enzyme assays growing strains were induced by addition of $0.1 \mathrm{mM} \mathrm{m}$-toluate in exponential phase and samples were collected after four hours of continued growth at $30^{\circ} \mathrm{C}$. Enzyme measurements ( $\beta$-lactamase and phosphoglucomutase assay) were performed according to the procedures described previously $[25,26]$. All enzyme activity analyses were repeated at least twice, and measurements were carried out with minimum three technical recurrences.

\section{Western blotting}

Cell samples were harvested by centrifugation $(8000 \mathrm{rpm}$, $5 \mathrm{~min}, 4^{\circ} \mathrm{C}$ ). Cell lysis was performed by resuspension of the pellets in $50 \mathrm{mM}$ Tris- $\mathrm{HCl}, \mathrm{pH} \mathrm{8.0,} \mathrm{addition} \mathrm{of} \mathrm{the}$ same volume of sucrose solution ( $40 \%$ sucrose containing $2 \mathrm{mM}$ EDTA in $50 \mathrm{mM}$ Tris- $\mathrm{HCl}, \mathrm{pH} 8.0), 125 \mathrm{UmL}^{-1}$ Benzonase Nuclease and $0.5 \mathrm{mg} \mathrm{mL}^{-1}$ lysozyme and incubation at room temperature with shaking for $1 \mathrm{~h}$. $3 \mathrm{x}$ sample buffer (150 mM Tris, pH 6.8, 30\% glycerol, 6\% SDS, $0.3 \%$ bromophenolblue, $300 \mathrm{mM}$ DTT) was added, samples were separated by SDS-PAGE (17\%, ClearPage, CBS Scientific) and transferred to a nitro-cellulose membrane. The membrane was blocked with Blotto and GM-CSF was detected by His-Probe-HRP in combination with ECL-substrate (Thermo Scientific) in Kodak Image Station 2000R (Kodak).

A plasmid with the wild-type expression cassette but containing the $\operatorname{trf} A$ variant $\operatorname{cop} 271 C$ [27] was used as positive control. This plasmid is maintained at a copy number 3.5 times higher than for plasmids with wildtype $\operatorname{trf} A$.

\section{RNA isolation, CDNA synthesis and qRT-PCR}

Strains were grown as described above (for enzyme assays). Cell cultures were stabilized with RNAprotect (Qiagen) prior to freezing and RNA was isolated from the frozen cell pellets using the RNAqeous kit (Ambion) as described by the manufacturers. The RNA preparations were treated with DNase (DNA-free, Ambion) and cDNA was produced from $3 \mathrm{mg}$ total RNA as template using the First-Strand cDNA synthesis kit (Amersham Biosciences) with random $\mathrm{pd}(\mathrm{N}) 6$ primers as described by the suppliers. Two-step qRT-PCR with the power SYBR green PCR master mix (Applied Biosystems) in a 7500 Real Time PCR System instrument (Applied Biosystems) was used for quantification of transcripts. PCR cycles were $95^{\circ} \mathrm{C}$ for $10 \mathrm{~min}$, followed by 40 cycles of amplification $\left(95^{\circ} \mathrm{C}\right.$ for $15 \mathrm{~s} ; 60^{\circ} \mathrm{C}$ for $\left.1 \mathrm{~min}\right)$. Results were analysed using 7500 system software v1.3, and data were normalized by the $2^{-\Delta \Delta C T}$ method [28]. Primers were designed using the primer express software (Applied Biosystems). Primer pairs used for transcript quantification were 5'-ACGTTTTCCAATGATGAGCACTT-3' and 5'-TGCCCGGCGTCAACAC-3' for bla, 5'-GTCCT CTTAGTTAAATGG-3' and 5'-AGGAATCGAACCTG C-3' for celB and 5'-CCCTGGGAGCATGTGAATG-3' and 5'-CATCTCAGCAGCAGTGTCTCTACTC-3' for gm-csf. $16 \mathrm{~S}$ rRNA gene (primer pair 5'-ATTGACGTT ACCCGCAGAAGAA-3' and 5'-GCTTGCACCCTCCG TATTACC-3') was used as a normalizer.

\section{Competing interests}

The authors declare that they have no competing interests.

\section{Authors' contributions}

FZ and RL were involved in all aspects of the experimental design and execution. All authors contributed to the writing of the manuscript. All authors read and approved the final manuscript.

\section{Acknowledgement}

We would like to thank to Trond Erik Vee Aune for the construction of the plasmid pTA16.

Received: 21 June 2012 Accepted: 22 September 2012 Published: 2 October 2012

\section{References}

1. Kumar PK, Maschke HE, Friehs K, Schugerl K: Strategies for improving plasmid stability in genetically modified bacteria in bioreactors. Trends Biotechnol 1991, 9:279-284.

2. Diaz Ricci JC, Hernandez ME: Plasmid effects on Escherichia coli metabolism. Crit Rev Biotechnol 2000, 20:79-108.

3. Hoffmann F, Rinas U: Stress induced by recombinant protein production in Escherichia coli. Adv Biochem Eng Biotechnol 2004, 89:73-92.

4. Bailey JE, Da Silva NA, Peretti SW, Seo JH, Srienc F: Studies of host-plasmid interactions in recombinant microorganisms. Ann N Y Acad Sci 1986, 469:194-211.

5. Dahlberg C, Chao L: Amelioration of the cost of conjugative plasmid carriage in Eschericha coli K12. Genetics 2003, 165:1641-1649.

6. Seo JH, Bailey JE: Effects of recombinant plasmid content on growth properties and cloned gene product formation in Escherichia coli. Biotechnol Bioeng 1985, 27:1668-1674.

7. Summers DK: The kinetics of plasmid loss. Trends Biotechnol 1991, 9:273-278. 
8. Wang Z, Xiang L, Shao J, Wegrzyn A, Wegrzyn G: Effects of the presence of ColE1 plasmid DNA in Escherichia coli on the host cell metabolism. Microb Cell Fact 2006, 5:34.

9. Baneyx F: Recombinant protein expression in Escherichia coli. Curr Opin Biotechnol 1999, 10:411-421.

10. Striedner G, Pfaffenzeller I, Luchner M, Nemecek S, Grabherr R, Bayer K. Plasmid-Free T7-Based Escherichia coli Expression Systems. Biotechnol Bioeng 2010, 105:786-794.

11. Tyo KE, Ajikumar PK, Stephanopoulos G: Stabilized gene duplication enables long-term selection-free heterologous pathway expression. Nat Biotechnol 2009, 27:760-765.

12. Li M, Wang J, Geng Y, Li Y, Wang Q, Liang Q, Qi Q: A strategy of gene overexpression based on tandem repetitive promoters in Escherichia coli. Microb Cell Fact 2012, 11:19.

13. Sletta H, Nedal A, Aune TE, Hellebust H, Hakvag S, Aune R, Ellingsen TE, Valla S, Brautaset T: Broad-host-range plasmid pJB658 can be used for industrial-level production of a secreted host-toxic single-chain antibody fragment in Escherichia coli. Appl Environ Microbiol 2004, 70:7033-7039.

14. Sletta H, Tondervik A, Hakvag S, Aune TE, Nedal A, Aune R, Evensen G, Valla $\mathrm{S}$, Ellingsen TE, Brautaset $\mathrm{T}$ : The presence of $\mathrm{N}$-terminal secretion signal sequences leads to strong stimulation of the total expression levels of three tested medically important proteins during high-cell-density cultivations of Escherichia coli. Appl Environ Microbio/ 2007, 73:906-912.

15. Bakke I, Berg L, Aune TE, Brautaset T, Sletta H, Tondervik A, Valla S: Random mutagenesis of the $\mathrm{Pm}$ promoter as a powerful strategy for improvement of recombinant-gene expression. Appl Environ Microbiol 2009, 75:2002-2011.

16. Berg L, Lale R, Bakke I, Burroughs N, Valla S: The expression of recombinant genes in Escherichia coli can be strongly stimulated at the transcript production level by mutating the DNA-region corresponding to the 5'untranslated part of mRNA. Microb Biotechnol 2009, 2:379-389.

17. Vee Aune TE, Bakke I, Drablos F, Lale R, Brautaset T, Valla S: Directed evolution of the transcription factor XyIS for development of improved expression systems. Microb Biotechnol 2010, 3:38-47.

18. Lale R, Berg L, Stuttgen F, Netzer R, Stafsnes M, Brautaset T, Vee Aune TE, Valla $S$ : Continuous control of the flow in biochemical pathways through $5^{\prime}$ untranslated region sequence modifications in mRNA expressed from the broad-host-range promoter Pm. Appl Environ Microbiol 2011, 77:2648-2655

19. Ramos JL, Stolz A, Reineke W, Timmis KN: Altered effector specificities in regulators of gene expression: TOL plasmid xylS mutants and their use to engineer expansion of the range of aromatics degraded by bacteria. Proc Natl Acad Sci USA 1986, 83:8467-8471.

20. Winther-Larsen $\mathrm{HC}$, Josefsen KD, Brautaset T, Valla S: Parameters affecting gene expression from the $\mathrm{Pm}$ promoter in gram-negative bacteria. Metab Eng 2000, 2:79-91.

21. Blatny JM, Brautaset T, Winther-Larsen HC, Karunakaran P, Valla S: Improved broad-host-range RK2 vectors useful for high and low regulated gene expression levels in gram-negative bacteria. Plasmid 1997, 38:35-51.

22. Haldimann A, Wanner BL: Conditional-replication, integration, excision, and retrieval plasmid-host systems for gene structure-function studies of bacteria. J Bacteriol 2001, 183:6384-6393.

23. Vethanayagam JG, Flower AM: Decreased gene expression from T7 promoters may be due to impaired production of active T7 RNA polymerase. Microb Cell Fact 2005, 4:3.

24. Blattner FR, Plunkett G 3rd, Bloch CA, Perna NT, Burland V, Riley M, ColladoVides J, Glasner JD, Rode CK, Mayhew GF, et al: The complete genome sequence of Escherichia coli K-12. Science 1997, 277:1453-1462.

25. Winther-Larsen HC, Blatny JM, Valand B, Brautaset T, Valla S: Pm promoter expression mutants and their use in broad-host-range RK2 plasmid vectors. Metab Eng 2000, 2(2):92-103.

26. Fjaervik E, Frydenlund $K$, Valla $S$, Huggirat $Y$, Benziman M: Complementation of cellulose-negative mutants of Acetobacter xylinum by the cloned structural gene for phosphoglucomutase. FEMS Microbiol Lett 1991, 77:325-330.
27. Durland $\mathrm{RH}$, Toukdarian A, Fang F, Helinski DR: Mutations in the trfA replication gene of the broad-host-range plasmid RK2 result in elevated plasmid copy numbers. J Bacteriol 1990, 172:3859-3867.

28. Livak KJ, Schmittgen TD: Analysis of relative gene expression data using real-time quantitative PCR and the 2(-Delta Delta $C(T)$ ) Method. Methods 2001, 25:402-408.

doi:10.1186/1475-2859-11-133

Cite this article as: Zwick et al:: Strong stimulation of recombinant protein production in Escherichia coli by combining stimulatory control elements in an expression cassette. Microbial Cell Factories 2012 11:133.

\section{Submit your next manuscript to BioMed Central and take full advantage of:}

- Convenient online submission

- Thorough peer review

- No space constraints or color figure charges

- Immediate publication on acceptance

- Inclusion in PubMed, CAS, Scopus and Google Scholar

- Research which is freely available for redistribution

Submit your manuscript at www.biomedcentral.com/submit
C) BioMed Central 